\title{
ОПРЕДЕЛЕНИЕ ДИНАМИКИ ЭМИССИИ ФЕРОМОНОВ ИЗ ПРЕПАРАТИВНЫХ ФОРМ МЕТОДОМ РАДИОМЕЧЕНЫХ КОМПОНЕНТОВ
}

K. SIIRDE, V. SAPEGIN, I. KUDRJAVTSEV, K. LAATS. FEROMOONIDE EMISSIOONI DCNAATIDE MEETODIL

K. SIIRDE, V. SAPEGIN, I. KUDRYAVTSEV, K. LAATS. ESTIMATION OF THE DYNAMICS OF PHEROMONE EMISSION IROM DISPENSERS BY THE RADIOLABELED COMPONENTS METHOD

Для выявления биологически эффективных препаративных форм синтетических феромонов (диспенсеров) требуется установление динамики эмиссии из них активных компонентов. С этой целью часто используется метод определения остаточного количества аттрактанта в диспенсере после выдержки его в определенных условиях $\left[{ }^{1-3}\right]$, а также данные по его биологической активности $\left[{ }^{2}\right]$. Однако названный метод трудоемкий и не совсем точный, к тому же требует для каждого определения нескольких диспенсеров, а результаты биологической оценки сильно зависят от конкретных полевых условий.

В настоящей работе предложена новая методика, позволяющая непосредственно измерять скорость испарения феромонов из диспенсеров в течение всего цикла их работы при помощи радиомеченых компонентов феромонов и определять при этом влияние температуры воздуха на динамику эмиссии. Возможности предложенной методики ниже проиллюстрированы на примере определения динамики эмиссии геранилбутаноата - аттрактанта для щелкуна степного и посевного $\left[{ }^{4,5}\right]$ - из препаративных форм на основе натурального каучука [ $\left.{ }^{6}\right]$.

Синтез меченого по сложноэфирному остатку ${ }^{14} \mathrm{C}$ геранилбутаноата $98,5 \%$-ной чистоты проводили по известной методике из фракции монотерпеновых хлоридов хлортеломера изопрена и $\mathrm{Na-coли} \mathrm{бутановой} \mathrm{кис-}$ лоты, меченой по ${ }^{14} \mathrm{C}$, через хлористый геранилдиметилфениламмоний $\left[{ }^{7,8}\right]$ с выходом $44 \%$ на исходный геранилхлорид.

ГЖX-анализ препарата осуществляли на хроматографе «Хром-5» с ПИД, колонка стеклянная капиллярная, $47000 \times 0,3$ мм, жидкая фаза PDEAS, температура колонки $150^{\circ} \mathrm{C}$, испарителя $270^{\circ} \mathrm{C}$, скорость газаносителя (аргона) 2,0 мл/мин.

Приготовление диспенсеров с меченым по ${ }^{14} \mathrm{C}$ геранилбутаноатом. В качестве носителя геранилбутаноата в диспенсерах использовали диски из резины на основе натурального каучука весом 500 мг, диаметром 13 мм и высотой 4 мм. На диски наносили при их медленном перемешивании во вращающейся стеклянной колбе и одновременном испарении легколетучего растворителя раствор меченого геранилбутаноата в гексане с таким расчетом, чтобы после полного испарения растворителя диски содержали 5,10 и 50 мг геранилбутаноата. Изготовленные препараты имели радиационную активность в пределах $6 \cdot 10^{4}-1.2 \cdot 10^{5}$ Бк.

Определение скорости эмиссии аттрактантов проводили на установке, состоящей из последовательно соединенных трубками микрокомпрессора, пагревательного элемента и осушителя воздуха, ротаметра, термостатированной камеры с дверцей и термометром, ловушки. Камеру с десятью диспенсерами продували воздухом со скоростью потока $0,1 \mathrm{~cm} / \mathrm{c}$, расход которого (5-6 л/ч) контролировали ротаметром. Пары́ аттрактанта 
поглощались в ловушке, где в качестве абсорбера использовалась сцинтилляционная жидкость ЖС-8. Через определенные промежутки времени отбирали из ловушки аликвотные пробы и измеряли их радиационную активность на радиометре РЖС-5М. Скорость эмиссии меченых компонентов рассчитывали по данным измерения радиационной активности проб до и после проветривания диспенсеров.

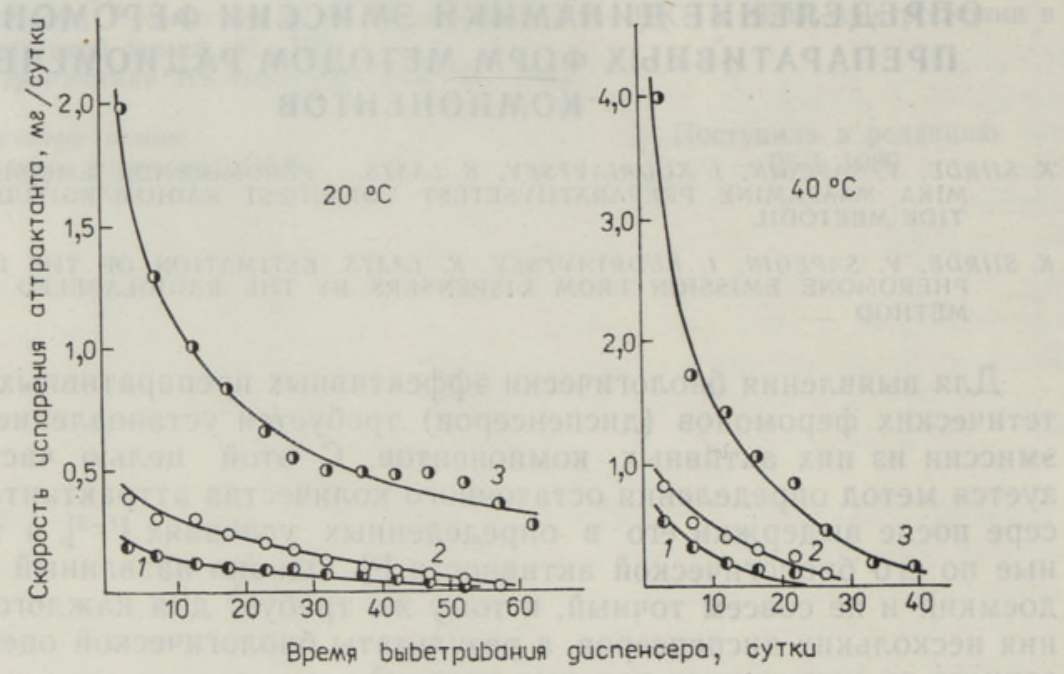

Динамика скорости испарения геранилбутаноата из диспенсеров на основе резины, нанесенного на диски в количестве 5 (1), 10 (2) и 50 мг (3).

Результаты измерений показывают (рисунок), что испарение геранилбутаноата из резины происходит неравномерно и зависит от исходного содержания на ней аттрактанта и температуры окружающей среды. Так, при исходном $2 \%$-ном содержании аттрактанта и температуре $20^{\circ} \mathrm{C}$ скорость испарения геранилбутаноата уменьшается от 0,4 до $0,01 \mathrm{mr} /$ сутки при длительности работы диспенсера 55 суток (кривая 2). При $9 \%$ ном содержании аттрактанта скорость испарения уменьшается от 2,0 до 0,2 мг/сутки в течение 70 дней, при этом убыль геранилбутаноата составляет $90 \%$ от исходного (кривая 3 ).

Повышение температуры среды от 20 до $40^{\circ} \mathrm{C}$ ускоряет эмиссию аттрактанта с сокращением времени работы диспенсера в среднем в 3 раза.

Полученные результаты совпадают с результатами по изучению динамики убывания геранилбутаноата из резиновых диспенсеров методом определения остаточных количеств аттрактанта в диспенсерах [9]. Это подтверждает применимость разработанного метода для оценки в лабораторных условиях динамики эмиссии и продолжительности работы феромонных диспенсеров в зависимости от температуры среды.

\section{ЛИТ Е Р А Т У Р А}

1. Лаанмаа М. К., Мыттус Э. Р., Кейсер Л. С. О методике определения $E, E-8,10$-додекадиен-1-ола в препаративной форме // Феромоны в защите сельскохозяйственных культур. Тарту, 1981, 153-154.

2. Колесова Д. А., Рябчинская Т. Л., Лаанмаа М. К., Мыттус Э. Р. Продолжительность действия различных препаратов синтетического феромона яблочной плодожорки (Laspeyresia pomonella L.) // Хеморецепция насекомых, 1984, № 8, $86-91$, 
3. Завелишко И. А., Черничук Л. Л. Характеристика процесса испарения феромона из препарата // Хеморецепция насекомых, 1987, № 9, 93-97.

4. Яцынин В. Г., Олещенко Н. Н., Рубанова Е. В., Нсмаилов В. Я. Идентификация активных компонентов половых феромонов щелкунов кубанского, степного и полосатого // Химия в с. х.; 1980, № 12, 33-35.

5. Яцынин В. Г., Карпенко Н. Н., Орлов В. Н. Половой феромон жука-щелкуна посевного // Химическая коммуникация животных. М., 1986, 53-57.

6. Список химических и биологических средств борьбы с вредителями, болезнями растений и сорняками и регуляторов роста растений, разрешенных для применения в сельском хозяйстве на 1986-1990 гг. // Защита растений, 1987, № 12, 47-52.

7. Лээтс $K$. В. К изучению ионно-каталитической теломеризации. III. О новом методе выделения первичных аллильных галоидпроизводных из смеси изомеров. Геранилхлорид. Сесквитерпеновые хлориды // Ж. общ. хим., 1961, 31, № 6, $1869-1876$.

8. Лээтс K. В. Способы получения сложных эфиров замещенных первичных аллиловых спиртов // А. с. № 130042 (СССР). Опубл. в Б. И., 1960, № 14, 15-16.

9. Верзунова Л. И., Лебедева В. В., Шейнина Е. В., Олещенко И. Н., Исмаилов В. Я., Лээтс К. В., Пасько А. К., Ранг Х. А., Кудрявцев И. Б. О результатах испытаний препаративных форм феромонов жуков-щелкунов // ВНИИХСЗР. М., 1988. 8 с. Деп. в ВИНИТи № 918-хп-86.

Ннститут химии

Академии наук Эстонской ССР
Поступила в редакцию 2//II 1989 